\title{
Cyclone and Tsunami Hazards in the Arabian Sea-A Numerical Modelling Case Study by Royal HaskoningDHV
}

\author{
M. A. Sarker ${ }^{1}$ and A. J. Sleigh ${ }^{2}$ \\ 1. Royal HaskoningDHV, Rightwell House, Bretton, Peterborough PE3 8DW, United Kingdom \\ 2. Royal HaskoningDHV, Stanley Hall, Edmund Street, Liverpool L3 9NG, United Kingdom
}

\begin{abstract}
Significant loss of life and damage to properties, ecosystems and marine facilities occur due to various natural hazards such as cyclones and tsunamis. Royal HaskoningDHV has developed regional hydrodynamic and wave models covering the Northern Arabian Sea to address these issues. Cyclone modelling was carried out on 11 major cyclones since 1945 and the tsunami modelling on an earthquake along the Makran Fault Line in 1945. Sample results from these modelling studies are presented in this paper. The methodology described in this article for modelling cyclones and tsunamis in the Arabian Sea could be applied to simulate these natural hazards at other sites around the world.
\end{abstract}

Key words: Numerical modelling, cyclone, tsunami, extreme waves, storm surge, port development, Arabian Sea.

\section{Introduction}

Various natural hazards such as cyclones and tsunamis impose significant risks during construction and operation of sea ports, oil terminals \& jetties, offshore exploratory drilling rigs and offshore oil extraction rigs. Furthermore, these natural hazards put lives and properties in coastal areas at greater risks. Significant loss of life, damage to properties, ecosystems and marine facilities occur due to these natural hazards.

A large tidal hydrodynamic model is required to simulate cyclone surge and tsunami heights on a region whereas a large wave model is required to simulate cyclone waves.

Royal HaskoningDHV has developed regional hydrodynamic and wave models covering the Northern Arabian Sea to investigate these natural hazards and support their project work in Oman. The

Corresponding author: Md Akhtaruzzaman Sarker, Ph.D., Principal Engineer, research field: numerical modelling of coastal processes including waves, tides, sediment transport, cyclones, tsunamis, ice and water quality (dredge plume, outfall discharge and oil spills). Email: zaman.sarker@rhdhv.com. models have been used to assess cyclones and tsunamis within the Arabian Sea. Cyclone modelling has concentrated on 11 major cyclones since 1945 and the tsunami modelling on an earthquake along the Makran Fault Line in 1945. Sample results from these modelling studies are presented in this paper for illustration purposes only.

The methodology described for modelling cyclones and tsunamis in the Arabian Sea could be applied to simulate these natural hazards at other sites around the world.

\section{Hydrodynamic Modelling}

\subsection{The Model}

Royal HaskoningDHV has developed a 2-dimensional Regional Tidal Hydrodynamic Model for the Northern Arabian Sea using the MIKE21/3 Flow Model FM software of DHI [1]. The model is based on the numerical solution of the two/three-dimensional incompressible Reynolds averaged Navier-Stokes equations invoking the assumptions of Boussinesq and of hydrostatic 
pressure. The regional model covers the coastlines of six countries i.e. Yemen, Oman, UAE, Iran, Pakistan and India (see Fig. 1). The model can be used in its own right to simulate tidal movements and surges within the Northern Arabian Sea as well as "building block" to drive a wide range of other models such as cyclone, tsunami, oil spill, water quality, sediment transport and morphological models. The model was used to drive the cyclone and tsunami models as described in the following sections.

\subsection{Methodology}

The model was set up in such a way that with a finer local mesh and more detailed bathymetry and land boundary data within a specified area, localised water movement can be accurately modelled at a point of interest without the need of introducing nested models. With this unstructured flexible mesh, it is easy to refine the mesh into an area of interest.

The model bathymetry is shown in Fig. 1 and was obtained from the C-Map Global Database [2]. The model has two open boundaries - one to the south and the other to the north-west. The model was driven by tide levels at these two boundaries obtained from the Global Tidal Model Database available within the MIKE21 Toolbox [3].

\subsection{Model Applications}

The tidal hydrodynamic model has been used to assess cyclone surge and tsunami heights within the region.

\section{Cyclone Modelling}

\subsection{The Model}

Royal HaskoningDHV has developed a 2-dimensional Regional Cyclone Model for the Northern Arabian Sea using the MIKE21/3 software. The cyclone model can be used to simulate both waves and surges for cyclones passing through the Northern Arabian Sea. The MIKE21 SW (Spectral Wave) Model was used to simulate the cyclone waves [4] and the MIKE21/3 Flow Model FM to simulate the cyclone surge [1]. The fully spectral formulation of the SW model is based on the wave action conservation equation, where the directional-frequency wave action spectrum is the dependent variable.

\subsection{Methodology}

Cyclones occur frequently in the Arabian Sea and can affect the Northern Arabian Sea Region. In particular, the passage of Cyclone Gonu (in 2007) and

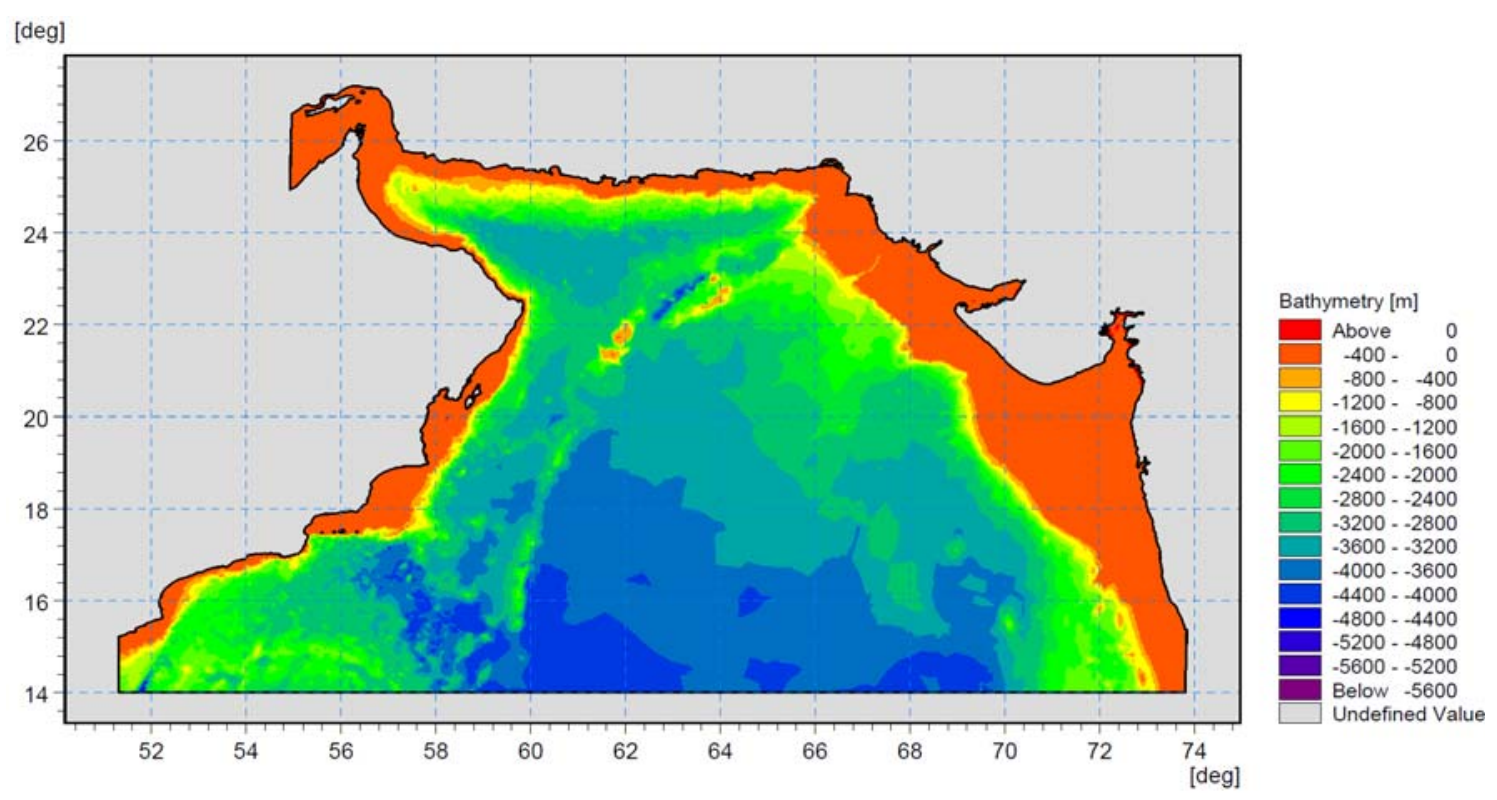

Fig. 1 Model extent and bathymetry. 


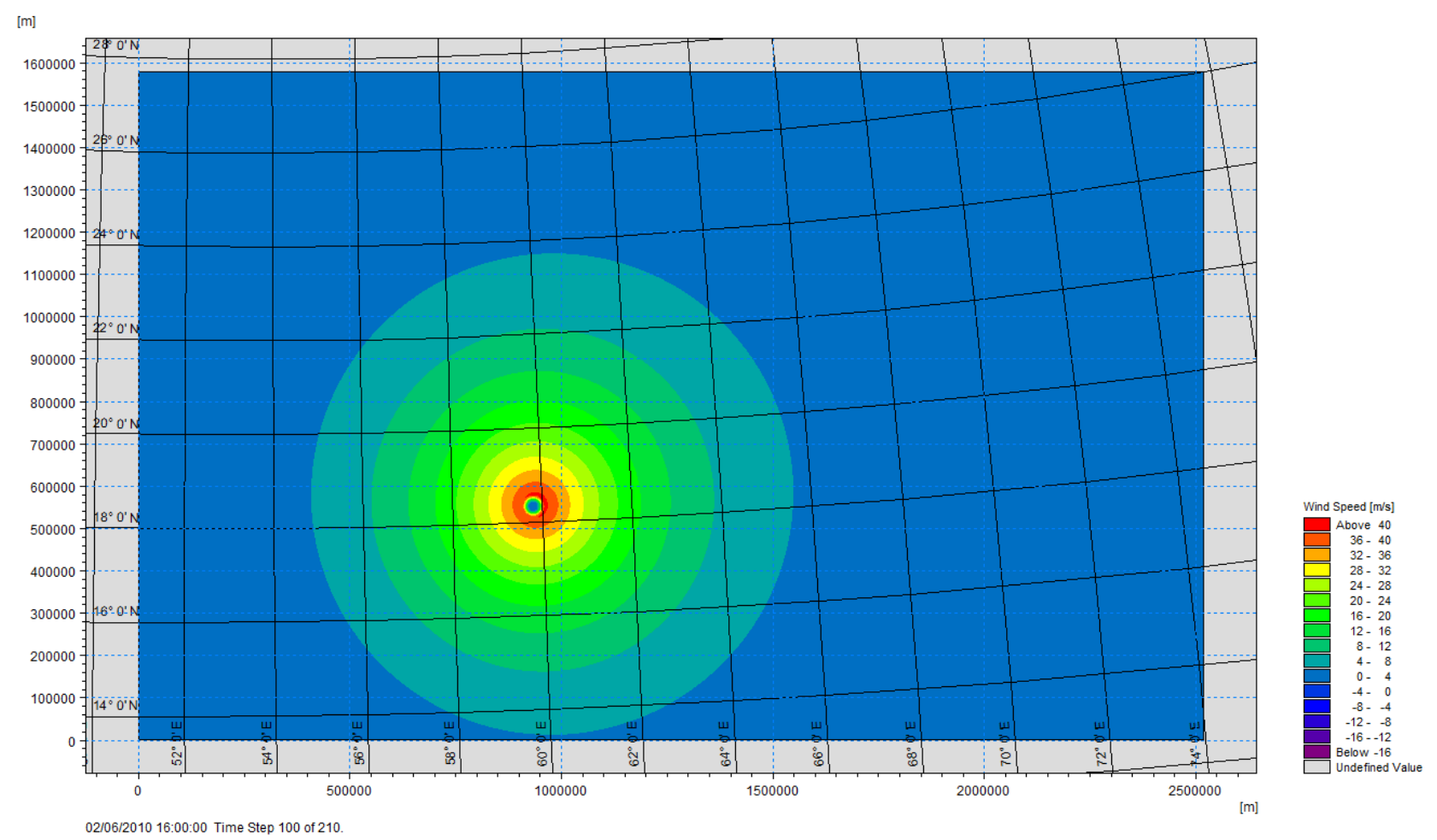

Fig. 2 Wind fields of Cyclone Phet (2010).

Cyclone Phet (in 2010) into the Gulf of Oman has raised awareness of the risk of events affecting the Omani coastline north of Ras Al Hadd. Since 1945 a total of 28 cyclones were initially identified to have crossed the Arabian Sea and affected the Omani coastline. A total of 11 cyclones were finally selected from the pool of 28 based on a combination of severity (wind speed and, central pressure and diameter) and the proximity to the site of interest. These 11 cyclones were simulated in the study.

Tracks and pressure fields of the selected cyclones were obtained from the Joint Typhoon Warning Centre, USA [5]. The MIKE21 Toolbox [3] was used to derive wind and pressure fields (as shown in Figs. 2 and 3) from the cyclone tracks and central pressures. The tool allows users to compute wind and pressure data due to tropical cyclone (hurricane or typhoon). All the parameters required by the Young and Sobey (1981) [3] model were available for the study and this was, therefore, used to generate the cyclonic wind and pressure fields. The cyclone model was driven by these wind and pressure fields.

\subsection{Model Validation}

Wave heights, periods and directions were extracted from model results at selected locations and were compared to those obtained from various sources to validate the model and thereby to improve confidence in model prediction.

\subsubsection{Comparison for Cyclone Gonu (2007)}

There are limited data to validate the cyclone modelling. Most of the available information was for Cyclone Gonu (2007) and therefore the model validation was focused primarily on this cyclone. Table 1 compares the model prediction with those observed by the Oman Meteorological Office [6] and the WMO (World Meteorological Organisation) [7].

The modelled wave heights at Chabahar and in the Gulf of Oman compared well with those reported by World Meteorological Organisation [7]. However, the modelled wave heights in the Arabian Sea are higher than those reported by WMO [7]. Similarly, the modelled wave heights in the Arabian Sea are higher than those reported by the Omani Meteorological Office 
Table 1 Comparison of cyclone results for Cyclone Gonu (2007).

\begin{tabular}{llll}
\hline \multirow{2}{*}{ Locations } & \multicolumn{3}{c}{ Maximum significant wave heights } \\
\cline { 2 - 4 } & World Meteorological Organisation [7] & Oman Met Office [6] & Present study \\
\hline Measurement point AW2 at Chabahar in Iran & $4.2 \mathrm{~m}$ & - & $4.5 \mathrm{~m}$ \\
at 30m depth & $8 \mathrm{~m}$ & - & $9 \mathrm{~m}$ \\
Gulf of Oman & $>11 \mathrm{~m}$ & $6-12 \mathrm{~m}$ & Up to $15 \mathrm{~m}$ \\
\hline
\end{tabular}

Table 2 Comparison of cyclone results for Cyclone Phet (2010).

\begin{tabular}{lll}
\hline \multirow{2}{*}{ Locations } & \multicolumn{2}{c}{ Maximum significant wave heights } \\
\cline { 2 - 3 } & Oman Met Office [6] & Present study \\
\hline Gulf of Oman & $4 \mathrm{~m}$ & $4 \mathrm{~m}$ \\
Arabian Sea & 7 to $8 \mathrm{~m}$ & $13 \mathrm{~m}$ \\
\hline
\end{tabular}

[6], however, the range of significant wave heights provided by the Omani Meteorological Office [6] is rather wide (6-12 m). Maximum significant wave heights of over $11 \mathrm{~m}$ in the Arabian Sea were reported by WMO [7]. On the other hand, maximum wave height of up to $15 \mathrm{~m}$ was found in the present study. It should be noted that wave conditions at Chabahar by WMO [7] were measured using ADCP.

Although there are some differences in wave heights reported by other organisations, it is concluded that there is reasonable agreement in the pattern and magnitude of waves (particularly in the coastal zone).

3.3.2 Comparison for Cyclone Phet (2010)

Some information was also obtained on Cyclone Phet (2010) from literature search. Table 2 compares the model prediction with those provided by the Oman Meteorological Office [6].

The modelled wave heights in the Gulf of Oman are similar to those reported by the Omani Meteorological Office [6]. However, in the Arabian Sea the modelled wave heights are significantly higher than those reported by the Omani Meteorological Office [6].

\subsection{Model Results}

All 11 cyclones selected were simulated in the study and it was found that the Cyclone Phet (2010) was one of the most severe events. Only the model results from Cyclone Phet (2010) are presented to limit the length of the paper. Fig. 4 shows the maximum significant waves heights and Fig. 5 illustrates the maximum surge during the entire duration of Cyclone Phet. The cyclone generated maximum significant wave height of about $13 \mathrm{~m}$ in the Arabian Sea and about $4 \mathrm{~m}$ in the Gulf of Oman. The highest surge of approximately $1.0 \mathrm{~m}$ was found at the northern part of the Masirah Island.

\section{Tsunami Modelling}

\subsection{The Model}

Royal HaskoningDHV has developed a 2-dimensional Regional Tsunami Model for the Northern Arabian Sea using the MIKE21/3 Flow Model FM software. The model can be used to simulate the propagation of tsunami waves and to predict their height and forward velocity within the Northern Arabian Sea region.

\subsection{Methodology}

The 1945 Balochistan Earthquake in Pakistan occurred at 5:26 PST on 28 November 1945 with a magnitude of 8.1. The earthquake's epicentre was 97.6 km south-southwest of Pasni in Balochistan (Pakistan) and the resulting tsunami caused damage along the Makran coastal region. Deaths from the event were reported to be as many as 4,000 people. Furthermore, the tsunami caused catastrophic damage to properties and other coastal facilities. The model has been used to simulate the propagation of the tsunami following 


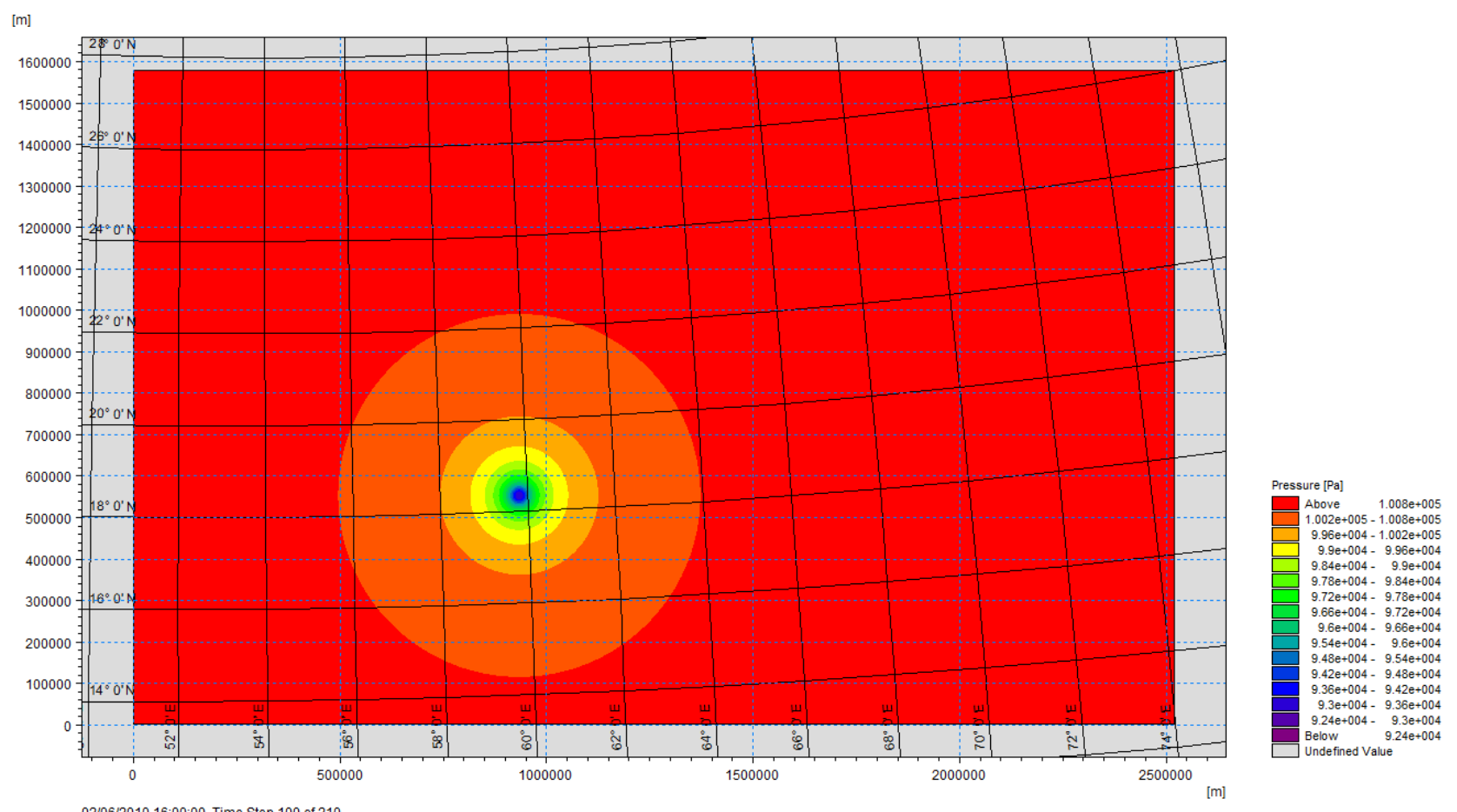

Fig. 3 Pressure fields of Cyclone Phet (2010).

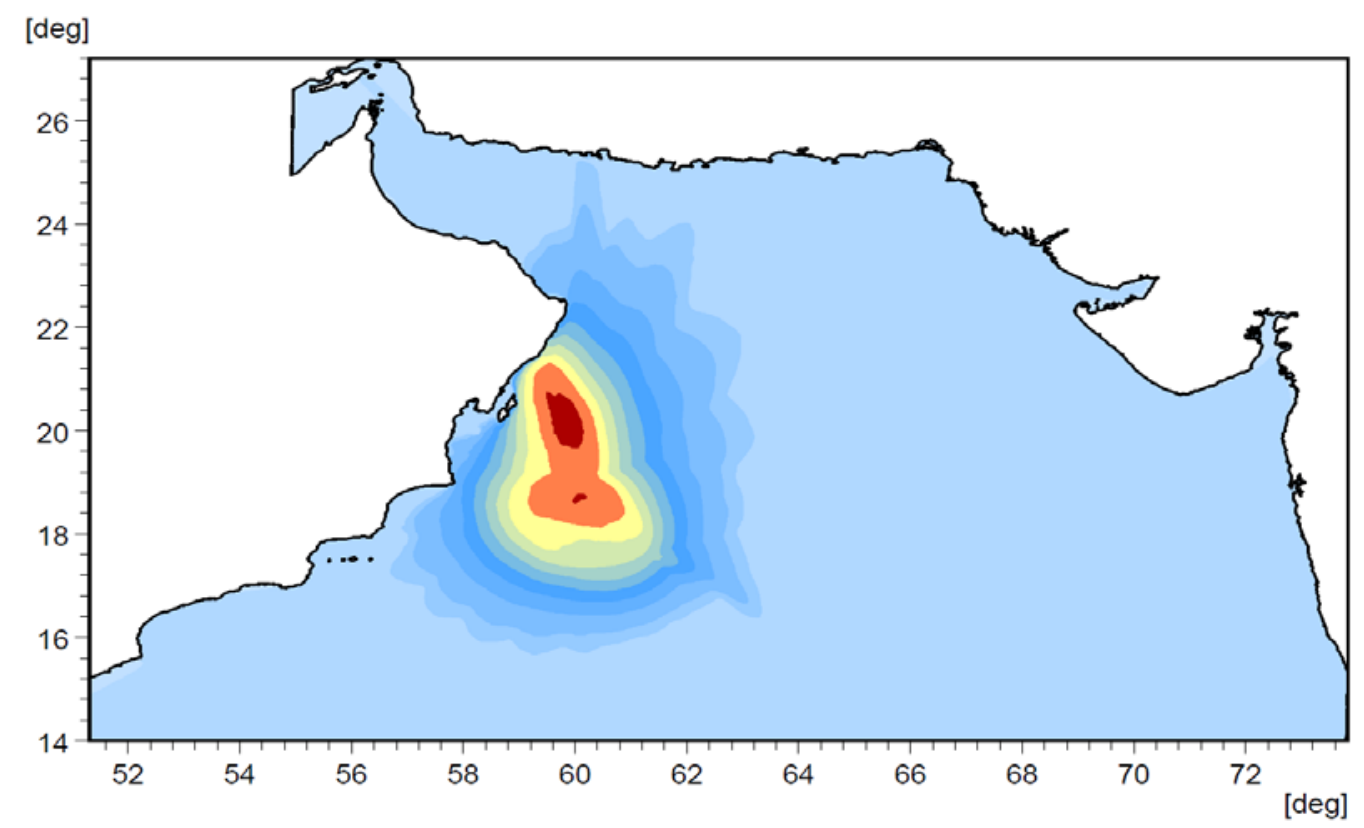

Statistical maximum : Sign. Wave Height [m]

Above 13.0 $12.0-13.0$ $11.0-12.0$ $10.0-11.0$ $9.0-10.0$ $8.0-9.0$ $7.0-8.0$ $6.0-7.0$ $5.0-6.0$ $4.5-5.0$ $1.0-4.5$ Below 1.0 Undefined Value

Fig. 4 Maximum significant wave heights during the entire duration of Cyclone Phet.

the initial rise in sea surface of about $2 \mathrm{~m}$ due to the movement along the Makran Fault Line as shown in Fig. 6.

\subsection{Model Validation}

Water levels predicted by Heiderzadeh et al. [8] are available at locations near Pasni (Pakistan) and Muscat (Oman) for the 1945 earthquake in the Makran Fault Line as shown in Fig. 7. The findings from Heiderzadeh et al. [8] study are given below:

The Iranian-Pakistani coastline to the north of the Makran Fault Line in particular near Pasni was severely 


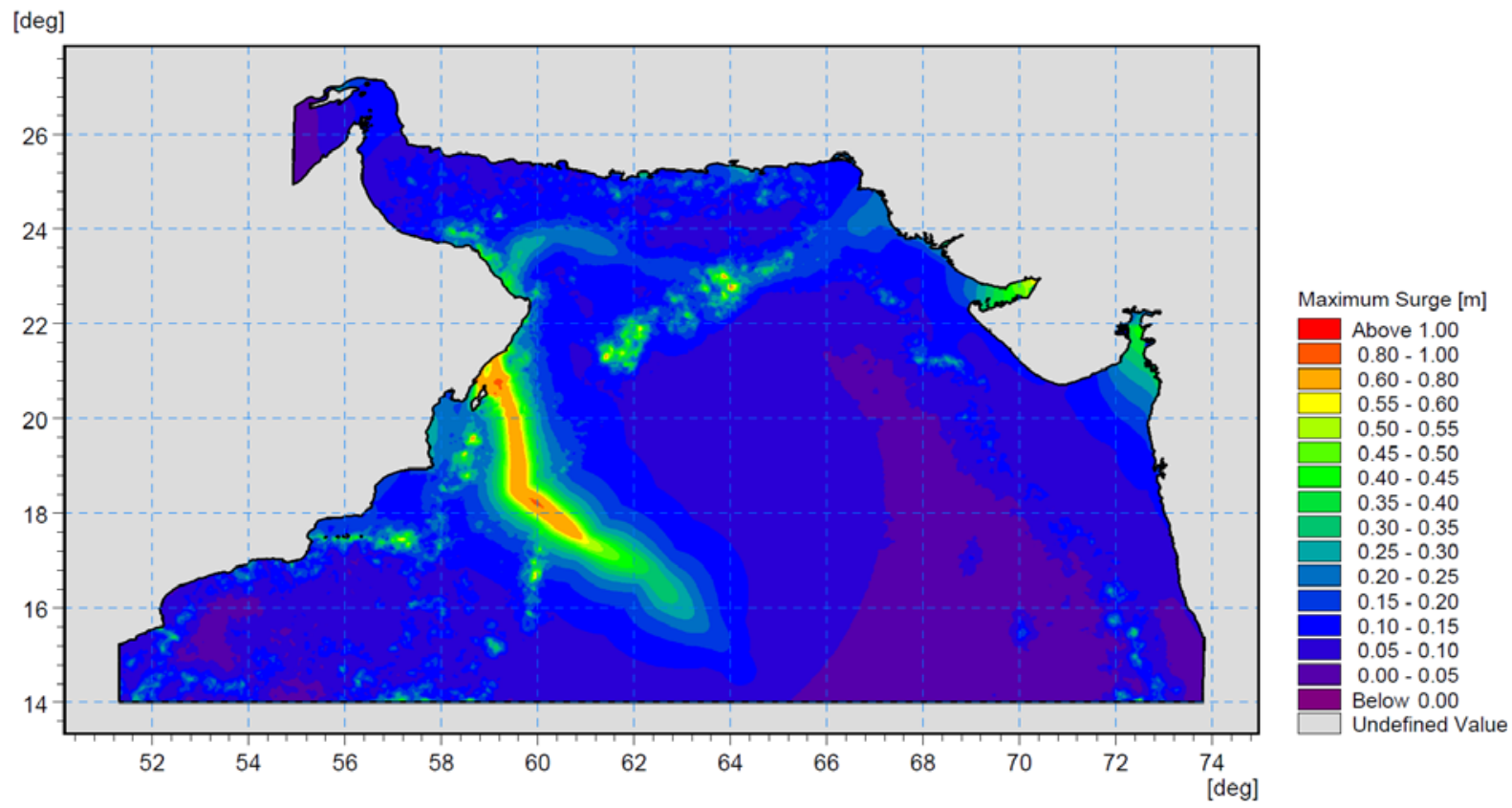

Fig. 5 Maximum surge during the entire duration of Cyclone Phet.

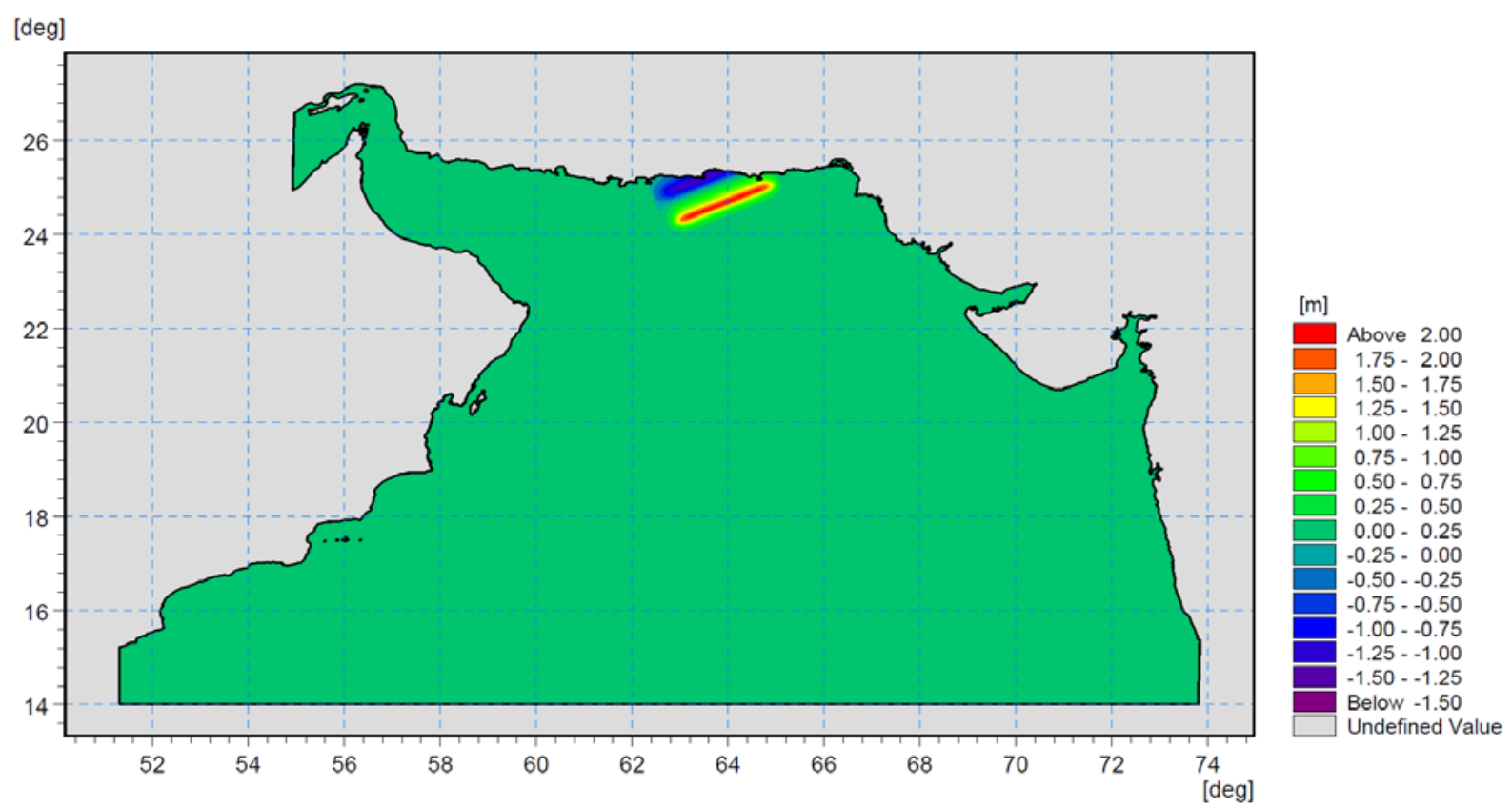

Fig. 6 Initial rise in sea surface during the 1945 tsunami.

affected. A rise in the sea surface near Pasni was generally about 4.5-5.5 m.

Their work shows that Muscat was less affected with a rise in the sea surface of about $0.30 \mathrm{~m}$.

Water levels were extracted from the present modelling study at locations near Pasni and Muscat as shown in Figs. 8 and 9. The findings are given below:
From the present study the predicted rise in the sea surface along the Iranian-Pakistani coastline to the north of the Makran Fault Line in particular near Pasni was approximately $4.3 \mathrm{~m}$.

The present study indicates that Muscat was less affected with a rise in the sea surface of approximately $0.22 \mathrm{~m}$. 


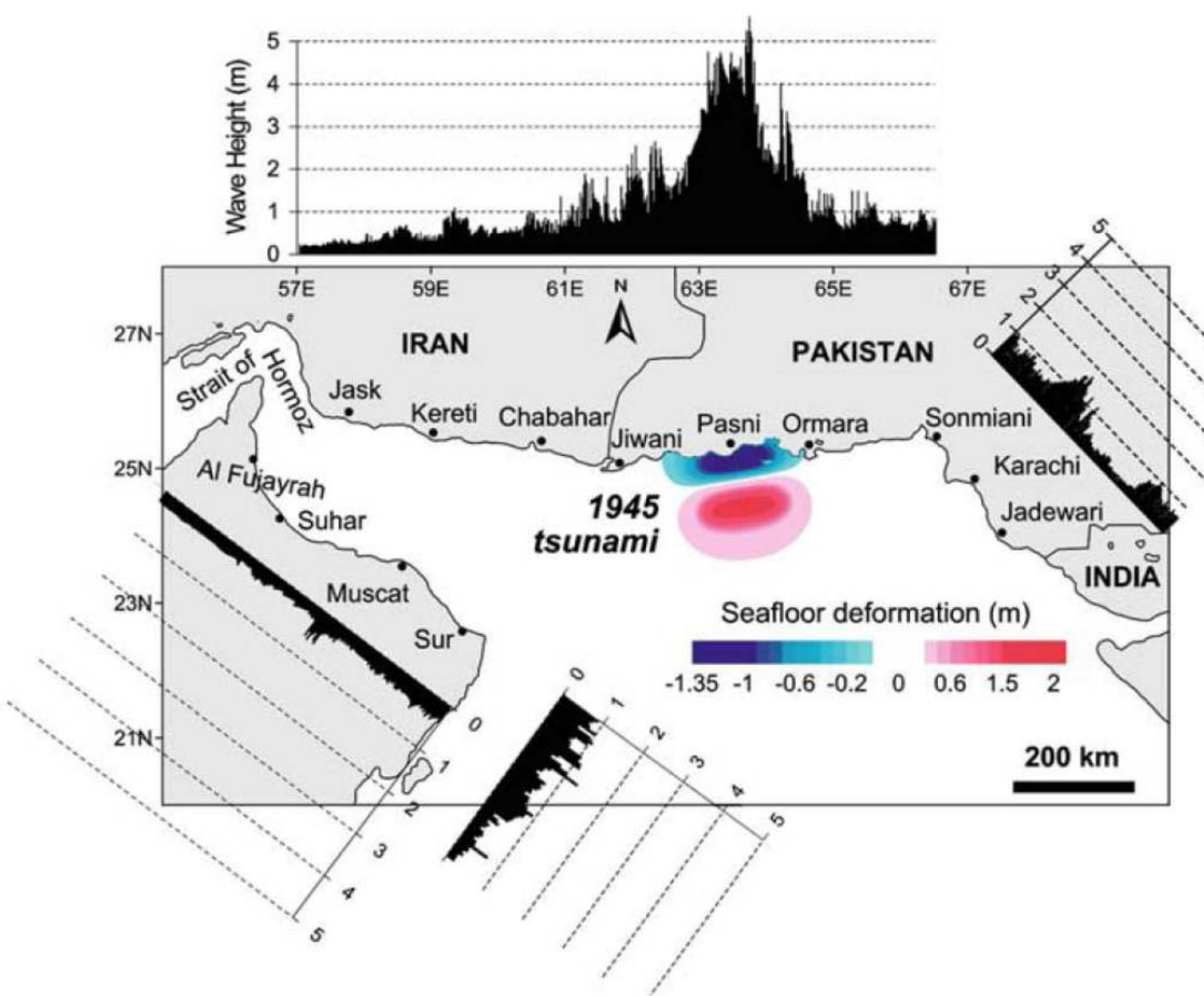

Fig. 7 Computed maximum tsunami levels along the coastal areas caused by the 1945 earthquake with Mw $=8.1$ [8].

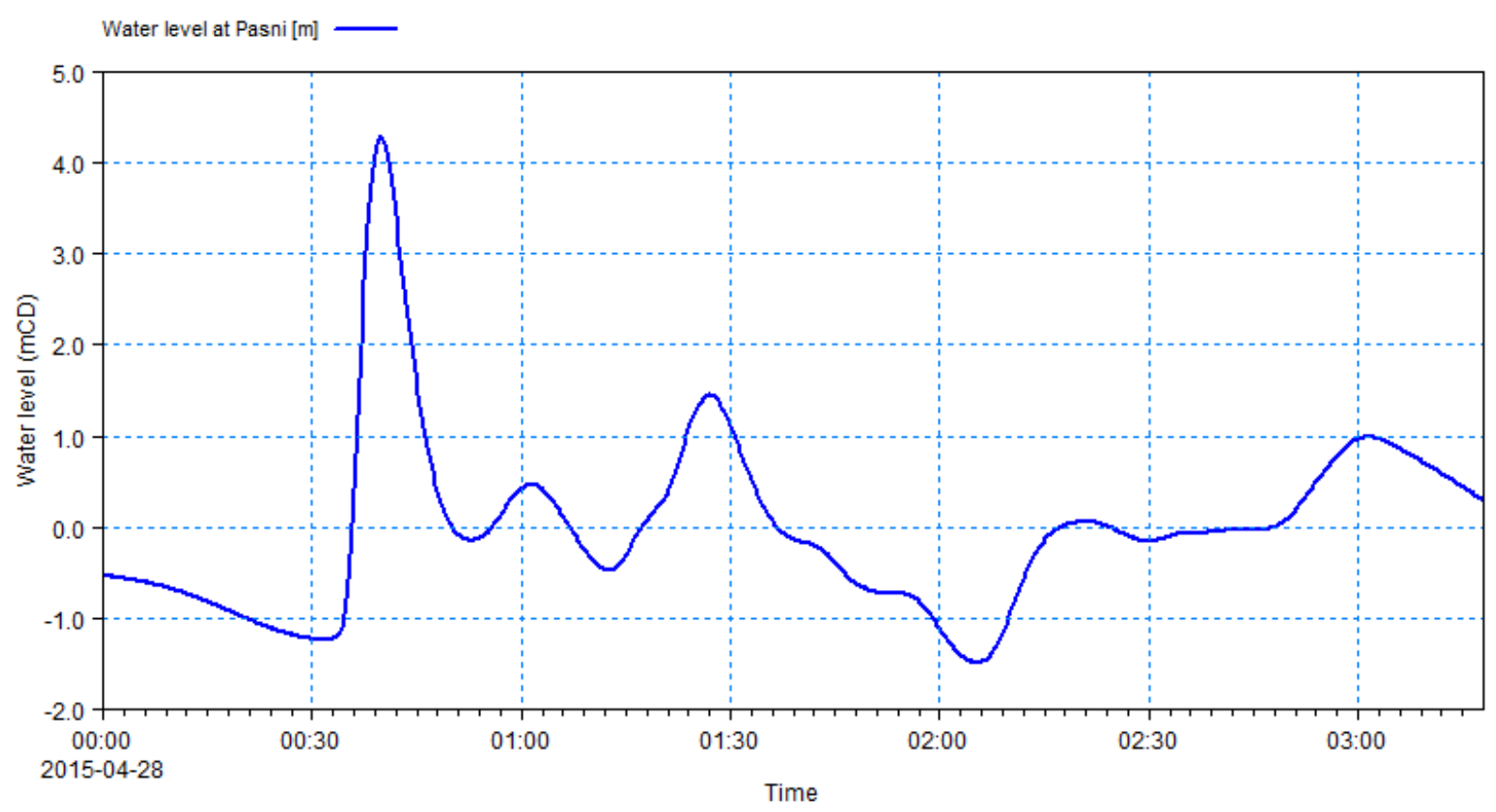

Fig. 8 Water levels near Pasni (Pakistan). 


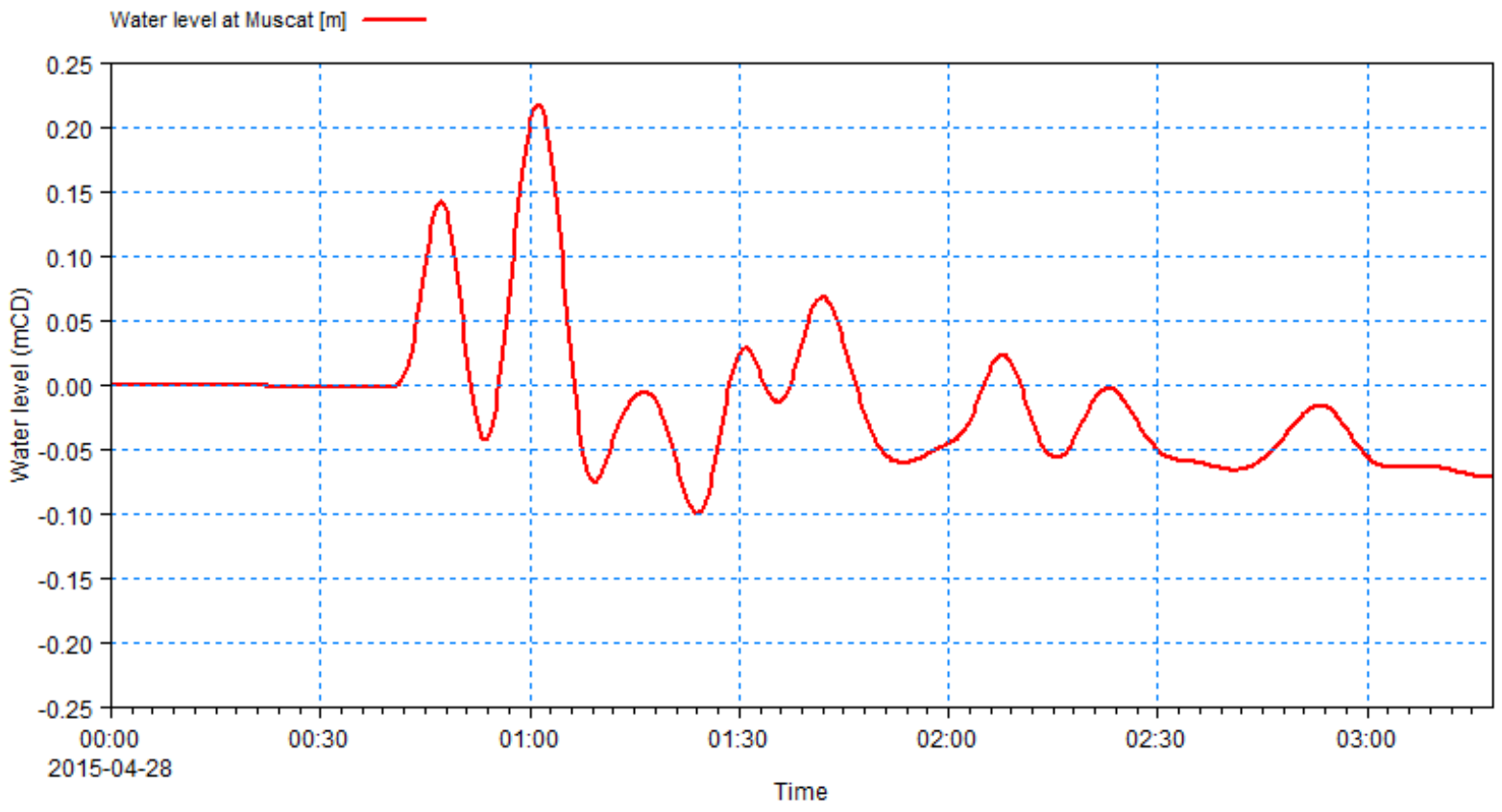

Fig. 9 Water levels near Muscat (Oman).

Table 3 Findings from the Heiderzadeh et al. [8] study and the present study.

\begin{tabular}{lll}
\hline Source of information & Water level rise near Pasni $(\mathrm{m})$ & Water level rise near Muscat $(\mathrm{m})$ \\
\hline Heiderzadeh et al. [8] & 4.5 to 5.5 & 0.30 \\
Present study & 4.3 & 0.22 \\
\hline
\end{tabular}

The findings from the Heiderzadeh et al. [8] study and the present study are summarised in Table 3.

A good agreement was found both in the pattern and the magnitude of the sea surface rise near Pasni and Muscat between the Heiderzadeh et al. [8] study and the present study. Therefore, it is concluded that the present model is capable of predicting the sea surface rise with an acceptable level of confidence.

\subsection{Model Results}

The propagation of tsunami waves over time was extracted from model results as illustrated in Fig. 10. The model results indicate that it will take approximately 15 minutes for the tsunami to reach Pasni, less than 30 minutes to reach Muscat and less than one hour to reach Masirah Island. Fig. 11 illustrates the maximum sea surface elevation during the entire passage of the tsunami. The coastal areas north of the Makran Fault Line are the worst affected due to their close proximity to the fault. A rise in water level of $4.3 \mathrm{~m}$ was found at Pasni and $0.22 \mathrm{~m}$ at Muscat. The maximum current speeds during the entire duration of the tsunami are shown in Fig. 12. Again, the coastal areas north of the Makran Fault Line are the worst with maximum current speeds up to $3.2 \mathrm{~m} / \mathrm{s}$ predicted.

\section{Application of Modelling Results}

The results from the cyclone and tsunami models provide valuable information at all stages of a project including planning, design, environmental impact assessment, construction, operation, and de-commissioning. The model results can also be used in emergency planning and decision-making to estimate potential loss of life, damage to properties and marine facilities and to develop mitigation measures and plan clean-up operations.

The regional tidal hydrodynamic model can be used to simulate tidal movements and surges as well as to drive a wide range of other models such as cyclone, 


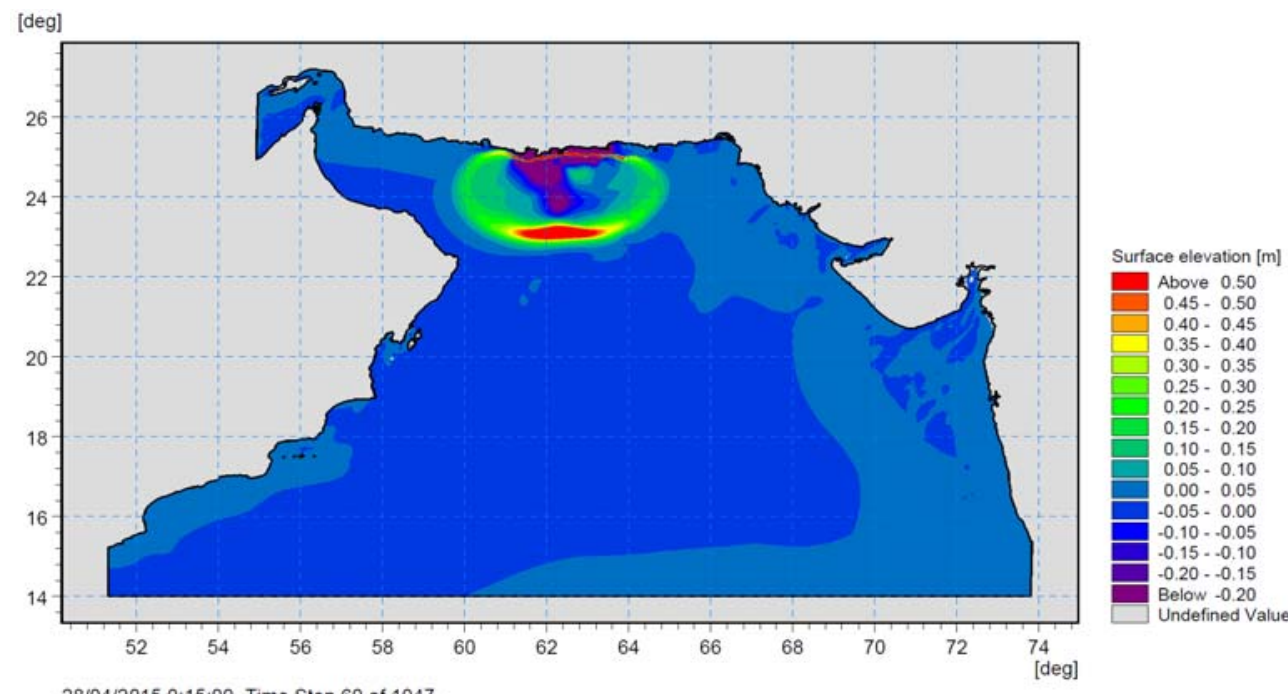

28/04/2015 0:15:00 Time Step 60 of 1047

(a) Tsunami waves after 15 minutes.
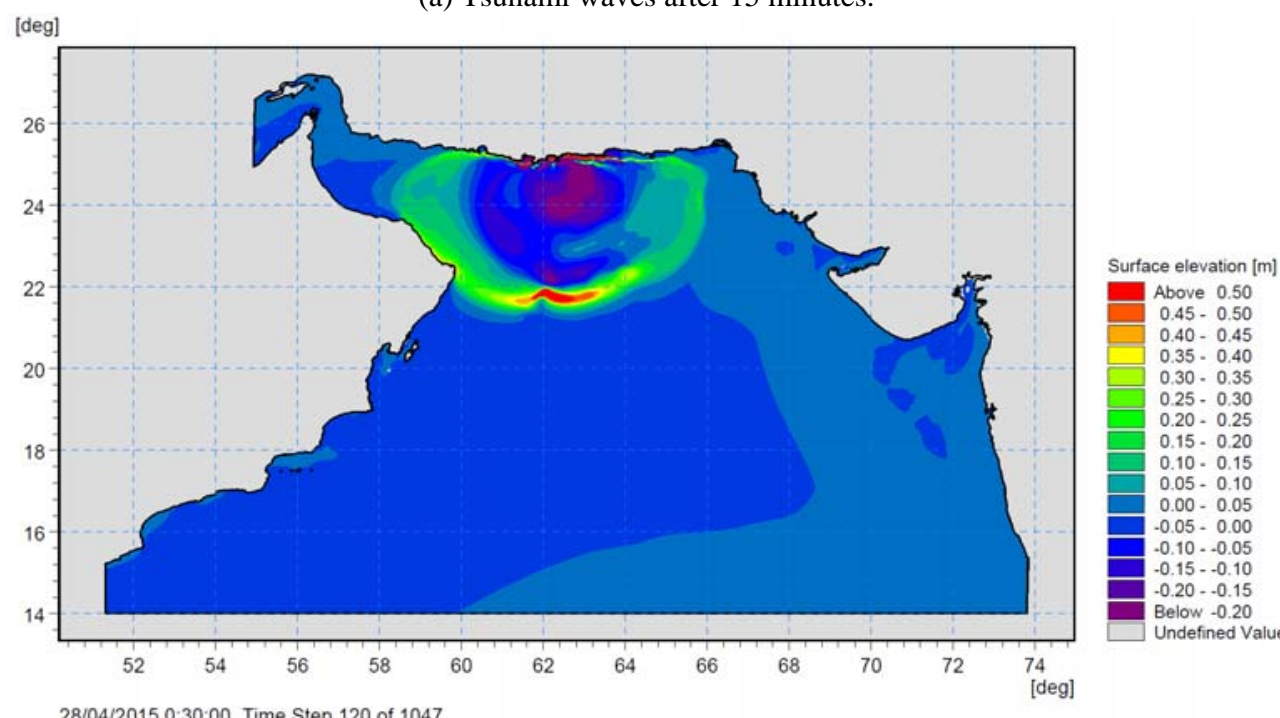

28/04/2015 0:30:00 Time Step 120 of 1047 .

(b) Tsunami waves after 30 minutes.

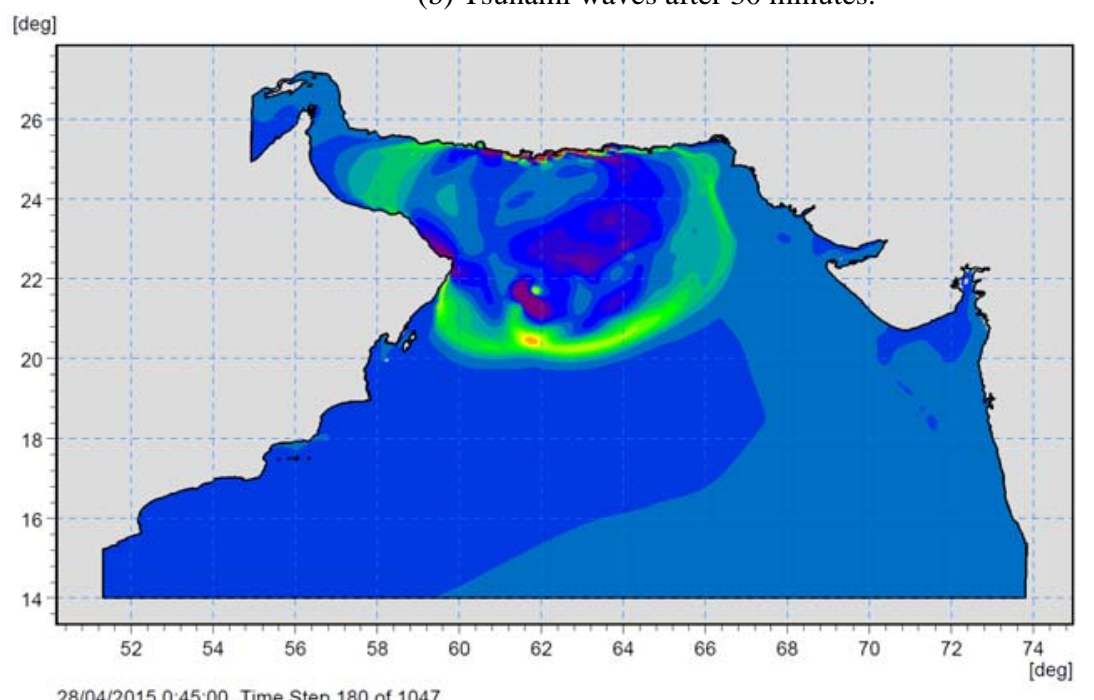

$0.35 \cdot 0.40$

$0.30-0.35$

$0.25-0.30$
$0.20-0.25$

$0.15-0.20$

$0.10-0.15$

$0.05 \cdot 0.10$

$-0.05 \cdot 0.00$

$-0.10 \cdot-0.05$
$-0.15--0.10$

$-0.20--0.15$

Below -0.20

28/04/2015 0:45:00 Time Step 180 of 1047 .

(c) Tsunami waves after 45 minutes. 

HaskoningDHV

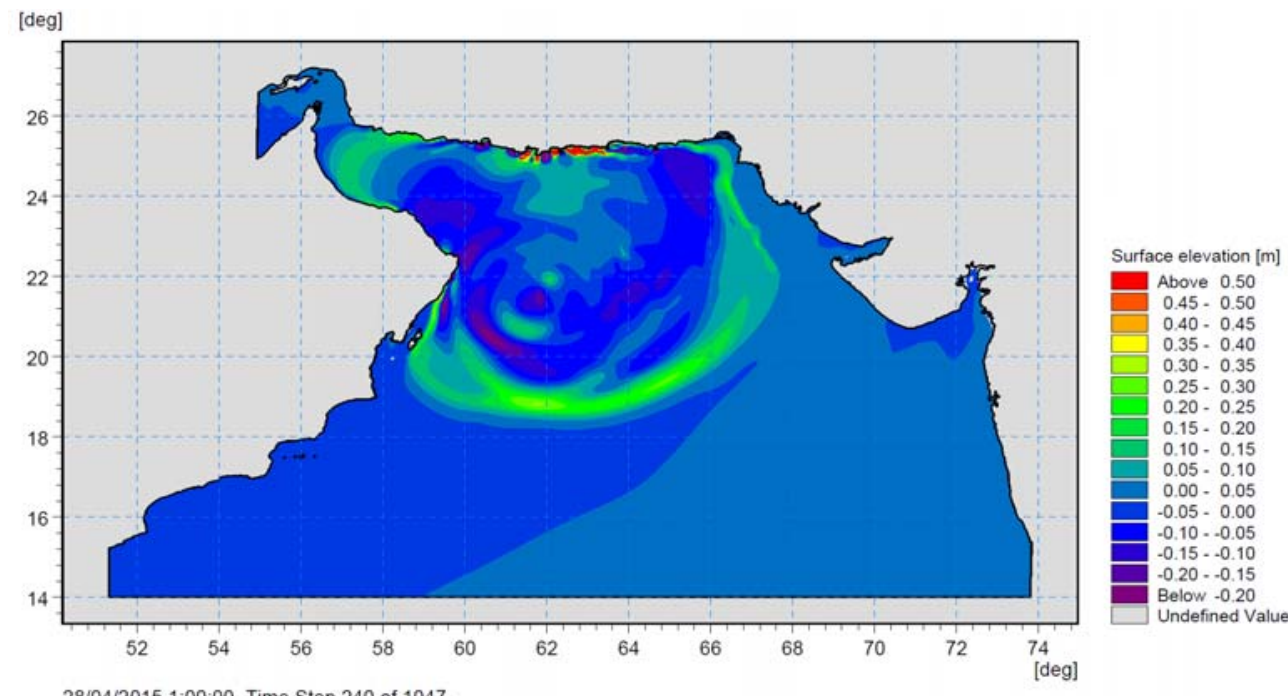

28/04/2015 1:00:00 Time Step 240 of 1047

(d) Tsunami waves after one hour.
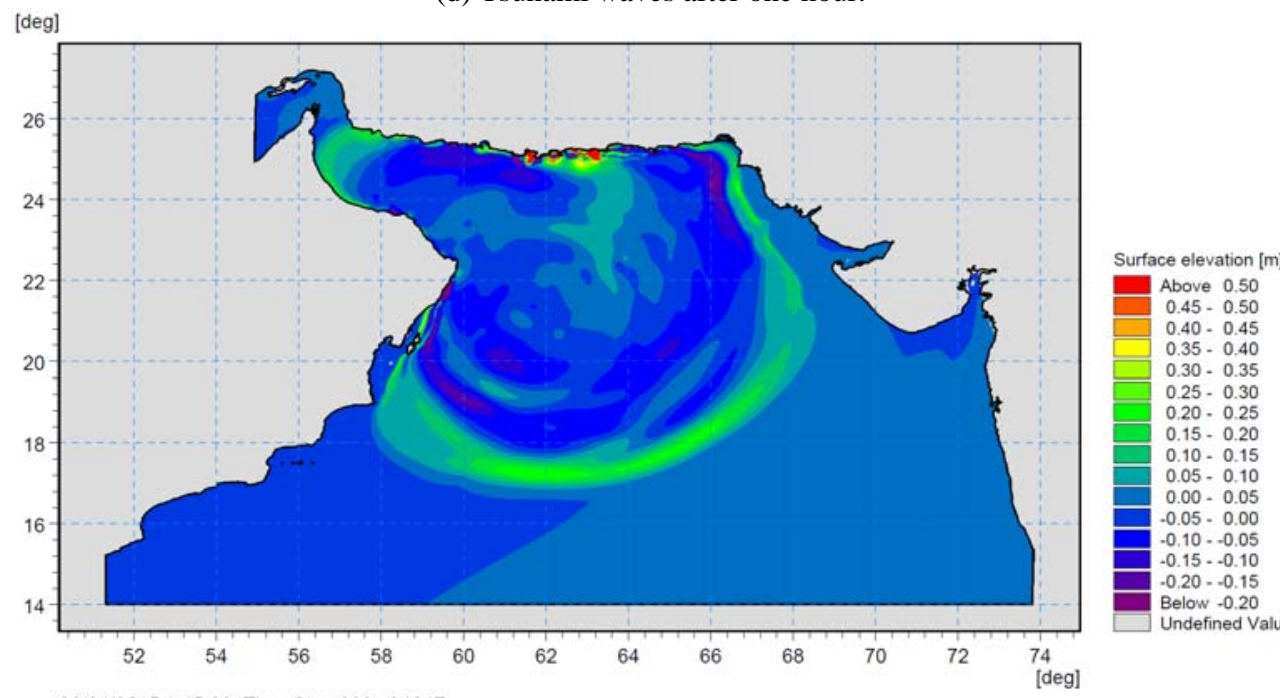

28/04/2015 1:15:00 Time Step 300 of 1047.

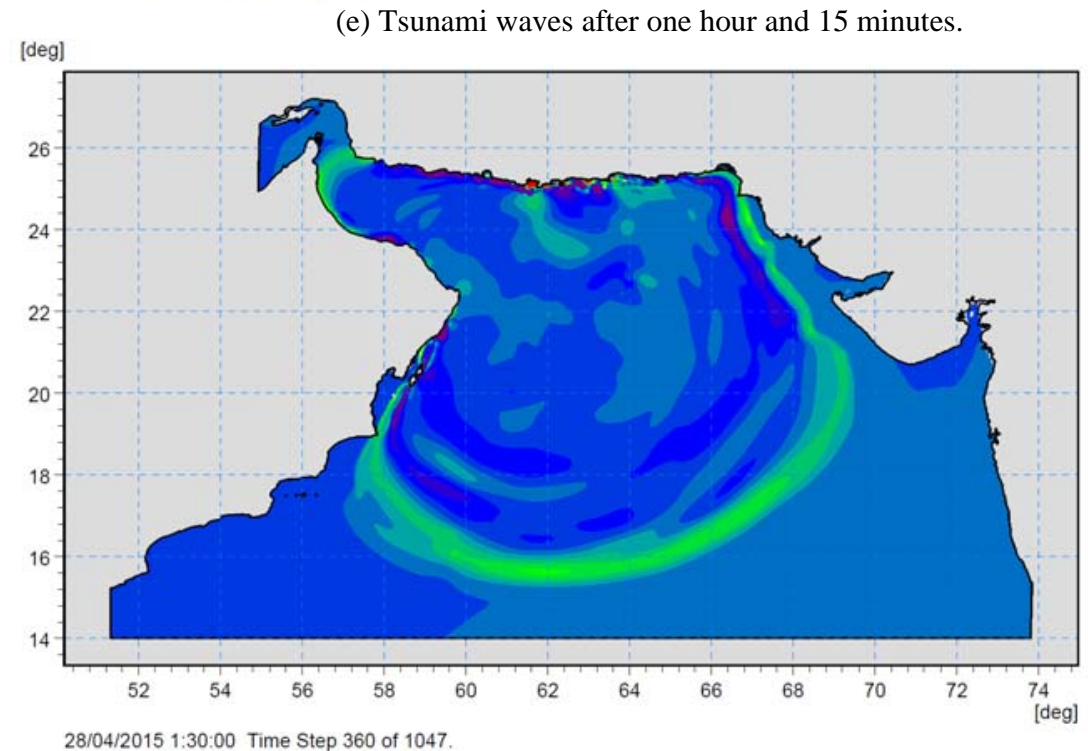

28/04/2015 1:30:00 Time Step 360 of 1047 .

(f) Tsunami waves after one hour and 30 minutes. 


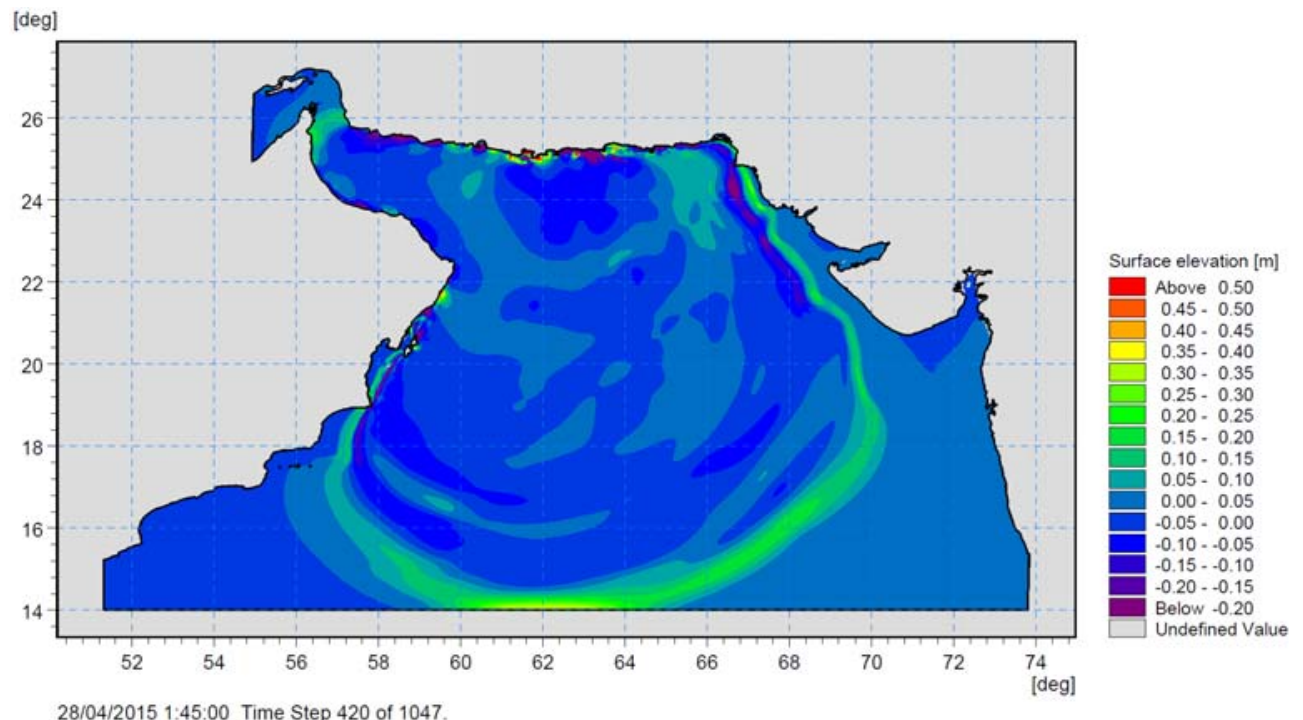

(g) Tsunami waves after one hour and 45 minutes.

Fig. 10 Tsunami wave propagation over time.

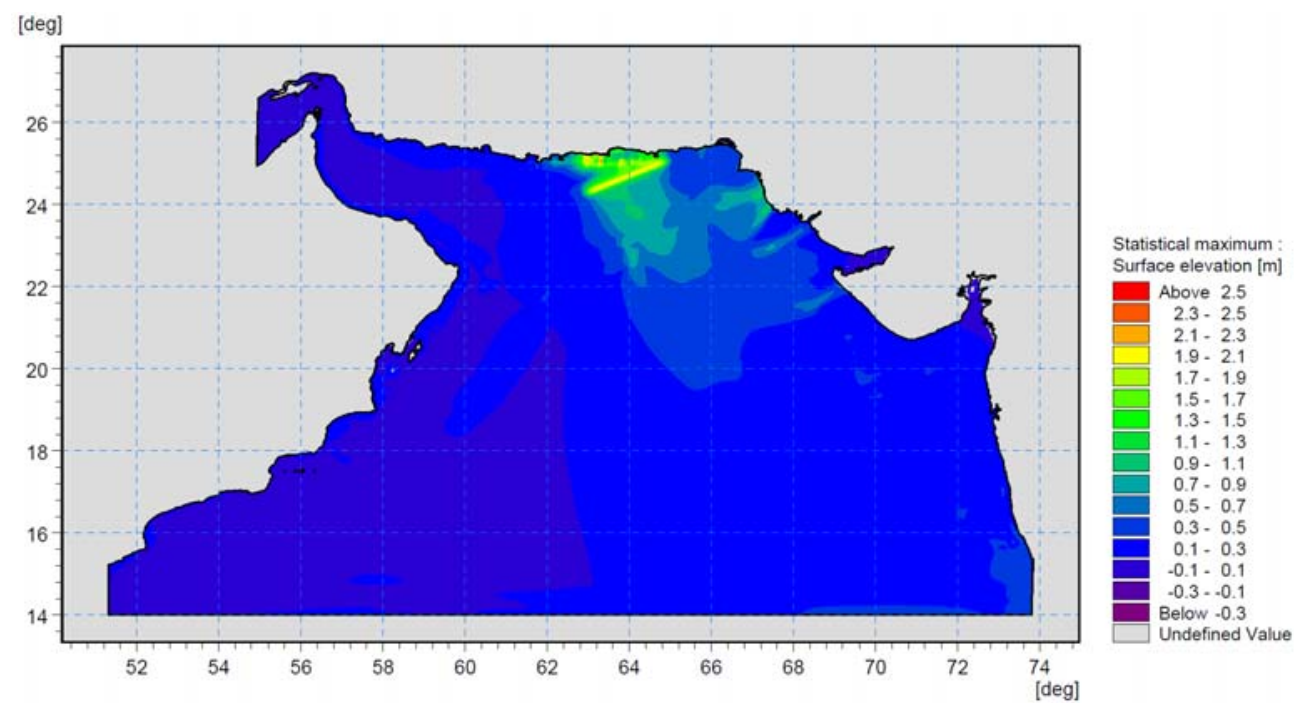

(a) Maximum sea surface elevation - entire domain.

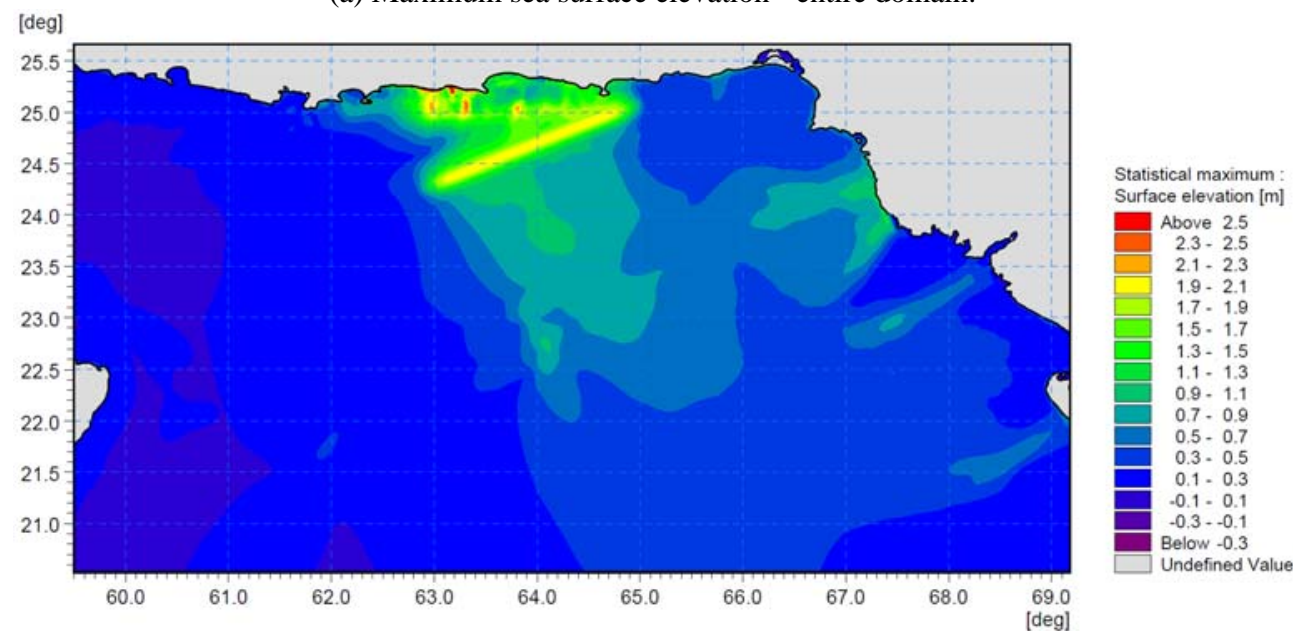

(b) Maximum sea surface elevation - zoomed in to the north.

Fig. 11 Maximum sea surface elevation during the entire duration of the tsunami. 


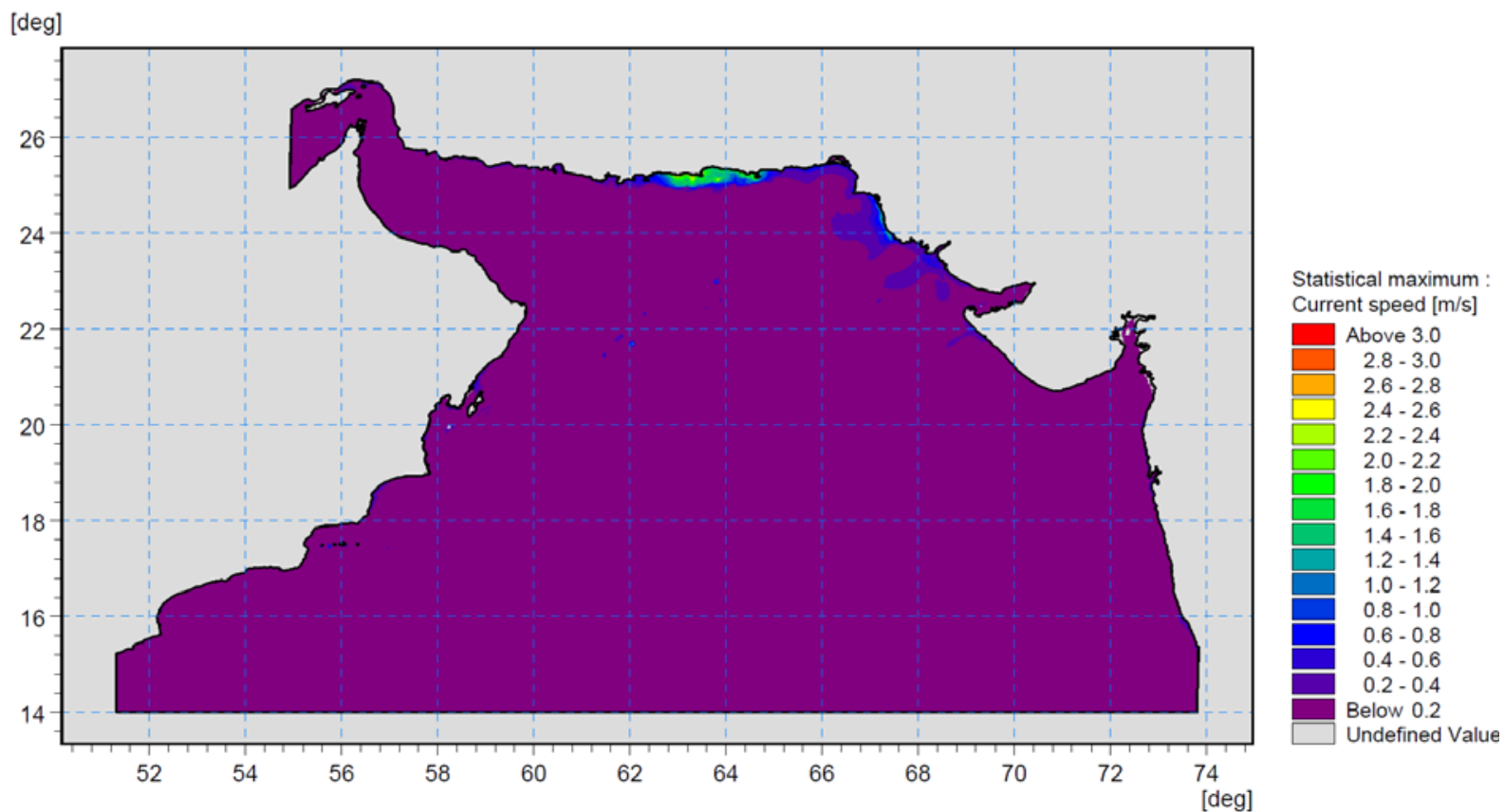

(a) Maximum current speeds - entire domain.

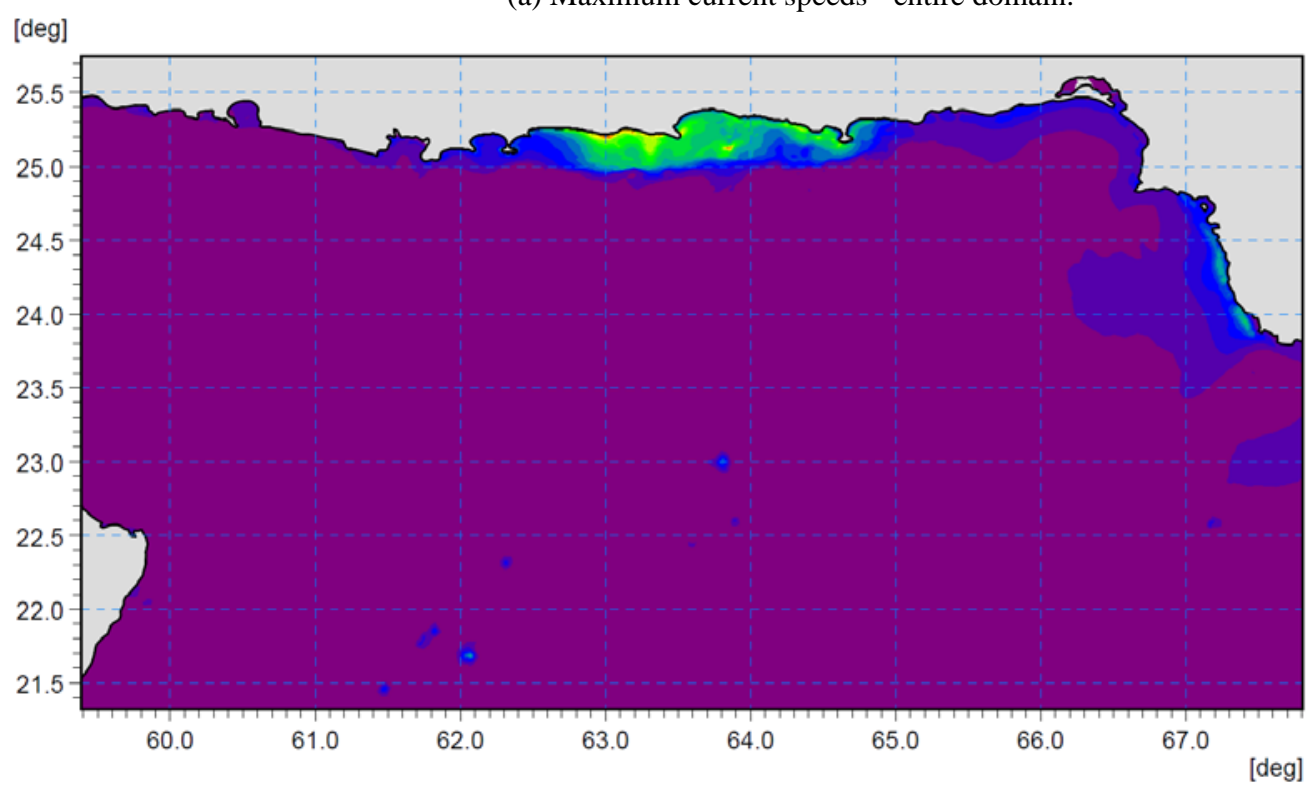

Statistical maximum Current speed $[\mathrm{m} / \mathrm{s}]$ Above 3.0

(b) Maximum current speeds - zoomed in to the north.

Fig. 12 Maximum current speeds during the entire duration of the tsunami.

tsunami, oil spill, water quality, sediment transport and morphological models.

The cyclone and the tsunami models are key tools for deriving robust design conditions for coastal and marine structures and facilities. The models can also provide input conditions to scale physical models for testing structural stability and overtopping rates and input to coastal flood studies.

\section{Conclusion}

This article illustrates how hydrodynamic and wave models can be used to simulate the impacts of cyclones and tsunamis on coastal developments and facilities. Although the emphasis has been on modelling these processes within the Arabian Sea, the methodology outlined in the article could be applied to 
sites within other regions that are affected by these natural hazards.

\section{Acknowledgements}

The authors would like to thank Royal HaskoningDHV (an independent, international engineering and project management consultancy company, www.royalhaskoningdhv.com) for giving permission to publish this article. For more details on this article and other numerical modelling work carried out by Royal HaskoningDHV worldwide, please contact Dr. Zaman Sarker (email: zaman.sarker@rhdhv.com).

\section{References}

[1] DHI. 2014. MIKE21 Flow Model FM User Guide, DK-2970, Hørsholm, Denmark.

[2] C-Map JEPPESEN Commercial Marine, Hovlandsveien 52, Egersund, Postal Code 4370,
Norway, 2014, available online at http://www.jeppesen.com/index.jsp.

[3] DHI. 2014. MIKE21 Toolbox User Guide, DK-2970, Hørsholm, Denmark.

[4] DHI. 2014 MIKE21 SW User Guide, DK-2970, Hørsholm, Denmark.

[5] The Joint Typhoon Warning Center (JTWC), the U.S. Department of Defense Agency, http://www.usno.navy.mil/JTWC.

[6] Ministry of Transport and Communications, Civil Aviation Affairs, General Directorate of Meteorological and Air Navigation, Department of Forecasting and Monitoring, Sultanate of Oman. Report adverse weather conditions for the special Tropical Cyclone (bit) (during the period May 31 to June 6, 2010).

[7] World Meteorological Organisation, WWRP 2010 - 2, $1^{\text {st }}$ WMO International Conference on Indian Ocean Tropical Cyclones and Climate Change, Muscat, Sultanate of Oman, 8-11 March 2009.

[8] Heidarzadeh M., Pirooz M. D., Zaker N. H., and Synolakis C. E. 2008. "Evaluating Tsunami Hazard in the Northwestern Indian Ocean.” Pure appl. geophys. 165 (2008): 2045-58. 